\title{
'Unrealistic' misconduct plans under fire
}

Washington. A group of prominent US scientific organizations is urging the US Department of Health and Human Services (DHHS) not to implement many of the recommendations of an independent commission on scientific misconduct, describing them as "inadequate", "inappropriate" and "unrealistic".

In particular, the scientific bodies complain that procedures proposed by the commission would unduly favour the accuser, making an accused researcher "guilty until proven innocent". They also claim that the commission has rejected a succinct and precise definition of misconduct, replacing it with one that is that is "overly broad, legalistic and open-ended".

But the commission's proposals have been defended by its chairman, Kenneth Ryan, emeritus professor of obstetrics, gynaecology and reproductive biology at Harvard Medical School. Ryan claims that the critics have exaggerated the potential intrusiveness of the suggested measures and have little experience of the pressure that can be put on 'whistleblowers'.

The complaints, which came from a group of 50 professional societies organized by the Federation of American Societies for Experimental Biology (FASEB), have been made about a report of the Commission on Research Integrity (CRI), requested by Congress and released last November.

The comments are made in a press release and a letter sent last week by Ralph Bradshaw, the president of FASEB and a professor of biological chemistry at the University of California, Irvine, to William Raub, the head of a panel of DHHS officials set up to recommend how to implement the CRI report.

According to FASEB, the biomedical and bioscience organizations that endorsed the letter represent more than 285,000 scientists. The suggestions of the panel headed by Raub are due to be presented to Donna Shalala, the secretary of DHHS, within several weeks. She will decide if and how they are adopted. Raub said last week that his panel is "giving consideration" to the letter, but declined to comment further.

The 50 organizations, which include the American Federation for Clinical Research, the American Association of Immunologists and the American Society of Human Genetics, also argue that the commission's suggestions would impose "intrusive, expensive, and time-consuming" regulations on research institutions.

The CRI report was drawn up over 17 months by a 12-member panel of nongovernment scientists, ethicists and lawyers. It was mandated by Congress, in the National Institutes of Health Revitalization Act of 1993, to develop a new definition of research misconduct, to develop regulations protecting whistleblowers and to suggest how to assure institutional compliance with DHHS regulations.

Current federal law defines scientific misconduct as "fabrication, falsification, plagiarism" or other practices that "seriously deviate" from those commonly accepted in the scientific community. Under the Public Health Service Act, this definition applies to all researchers funded by the National Institutes of Health (NIH), and some funded by other agencies.

In a report published in 1992, the National Academy of Sciences (NAS) recommended a narrower definition. It suggested that misconduct in science should be defined as "fabrication, falsification, or plagiarism, in proposing, performing, or reporting research" - excluding from the definition errors in data recording, selection, analysis and interpretation.

In contrast, the review commission suggests that the words "fabrication, falsification, or plagiarism" should be replaced by "misappropriation, interference, and misrepresentation". Some argue that this would

\section{Remote stargazing draws the young}

Geneva. Plans to extend a project that allows school pupils to operate researchgrade telescopes at a distance received a boost last week, when its founder Gilbert Clark - an engineer at the NASA/Caltech Jet Propulsion Laboratory (JPL) in Pasadena, California - was selected from thousands of applicants as one of the five winners of the 1996 Rolex Awards for Enterprise, presented in Geneva last week.

The Telescopes in Education (TIE) project lets pupils equipped with a computer and modem operate Caltech's 24-inch reflector telescope at the Mount Wilson Observatory outside Los Angeles. Using a 'point and click' planetarium interface, they can steer the telescope to photograph galaxies, nebulae and other objects, and download the images.

The Caltech telescope, which was used during the Apollo programme to verify that the Moon was not covered in a thick dust layer that would have swallowed a landing spacecraft, was put into mothballs in the 1970s. Three years ago, Clark persuaded Caltech to let him reinstall the telescope at the Mount Wilson Observatory with the support of its director, Robert Jastrow, and NASA (the National Aeronautics and Space Administration).

With the help of volunteers, Clark refurbished the telescope, fitted it with charge-coupled-device (CCD) cameras, and modified it so that it could be operated at a distance by computer. Now the telescope is booked up months in advance by cover significant failures in data collection and storage; unlike the academy, for example, the CRI proposal would punish intentional omissions from a scientific paper if they falsified the entire report.

Ryan argues that the academy's definition of misconduct is too narrow. "They only want to call misconduct outright fraud. I think it's very hard to draw that fine distinction," he said. But the FASEB statement claims that the commission's proposed definition could "stifle" intellectual creativity by opening scientists to "unpredictable and ill-defined" charges of misconduct.

The FASEB statement also challenges the CRI's recommendations of protection for whistleblowers, saying that these would "make the accuser part of the investigating team" without holding them accountable for "violations of confidentiality, false statements, or other unlawful behaviour". But Ryan argues that the FASEB scientists, have been "shielded" from the bad behaviour of institutions towards whistleblowers, while the balance of power is often "heavily tilted toward the accused". Meredith Wadman

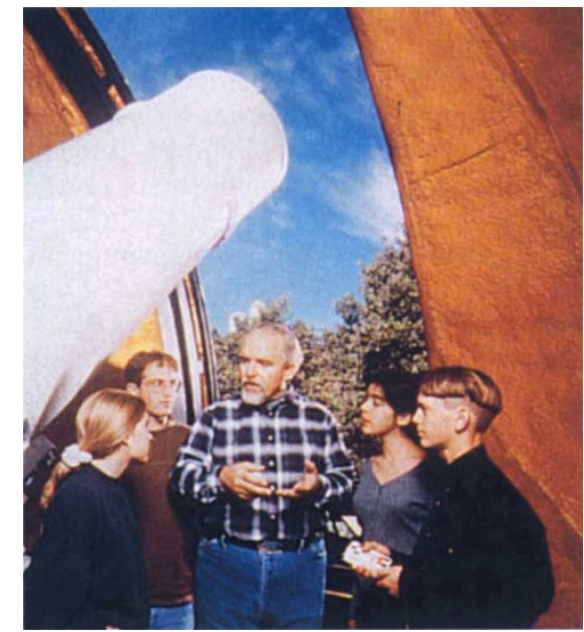

Looking up: Clark with Caltech telescope.

schools. Richard Yessayian, a science teacher in Los Angeles, describes the impact of the project on children's interest in science as "overwhelming".

Two of the American schools taking part in the TIE programme have already recalculated the orbit of Pluto, producing data that will be used by NASA in planetary missions.

Encouraged by the general response, Clark says he now plans to extend the programme. He hopes soon to include another telescope at Mount Wilson, four in Australia, and a radiotelescope. "We need at least 20 for an international network," says Clark.

Declan Butler 